\title{
Analisis Sistem Pendukung Keputusan Pemilihan Asisten Dosen Menggunakan MetodeSAW di STMIK Amikom Surakarta
}

\author{
Afnan Rosyidi ${ }^{1}$, Siti Rihastuti ${ }^{2}$ \\ STMIK Amikom Surakarta \\ Surakarta \\ Email :1afnan@dosen.amikomsolo.ac.id, \\ ${ }^{2}$ siti@dosen.amikomsolo.ac.id
}

\begin{abstract}
Abstrak
Asisten dosen merupakan sumber daya manusia yang sangat membantu dosen saat berlangsungnya matakuliah praktek. Agar asisten dosen yang direkut sesuai dengan kebutuhan dan memiliki kemampuan yang baik dalam mendampingi mahasiswa saat belajar di laboratorium, maka dalam penelitian ini diusulkan sebuah analisis slstem pendukung keputusan pemilihan asisten dosen di STMIK Amikom Surakarta. Metode yang digunakan untuk melakukan perhitungan dalam pemilihan asisten dosen adalah Simple Additive Weighting (SAW). Kriteria yang digunakan dalam pemilihan asisten dosen adalah minimal nilai ipk 3,0 dan jenjang semester minimal semester 3, nilai tes tertulis dan nilai tes wawancara. Hasil akhir dari perhitungan menggunakan SAW akan menjadi pertimbangan Ketua UPT laboratorium dapat menentukan mahasiswa yang lolos menjadi asisten dosen, yaitu mahasiswa yang telah menjalani seleksi dan memiliki urutan ranking berdasarkan nilai teratas hingga terbawah dari keseluruhan peserta yang mengikuti seleksi.
\end{abstract}

Kata Kunci: pemilihan asisten dosen, simple additive weighting, sistem pendukung keputusan

\begin{abstract}
Lecturer assistants are human resources who are very helpful for lecturers during practical courses. So that the lecturer assistants who are recruited are following with the needs and have good abilities in assisting students while studying in the laboratory, this study proposes an analysis of the decision support system for the selection of lecturer assistants at STMIK Amikom Surakarta. The method used to perform calculations in the selection of teaching assistants is Simple Additive Weighting (SAW). The criteria used in the selection of teaching assistants are a minimum GPA of 3.0 and a minimum semester level of 3rd semester, written test scores, and interview test scores. The final result of the calculation using SAW will be considered by the Head of the UPT laboratory to determine students who pass to become lecturer assistants, namely students who have undergone the selection and have a ranking order based on the highest to the lowest scores of all participants who took part in the selection.
\end{abstract}

Keywords: selection of lecturer assistants, simple additive weighting, decision supprot system

\section{PENDAHULUAN}

Tenaga pengajar (dosen) dalam kegiatannya melaksanakan pengajaran di kelas, sering membutuhkan asisten dosen terutama pada saat perkuliahan praktek dilaboratorium sedang berlangsung. Keberadaan asisten dosen sangat membantu dosen dalam menangani mahasiswa yang sedang praktek menggunakan aplikasi atau software sesuai matakuliah yang diajarkan. Asisten dosen membantu mahasiswa memahami ilmu praktek yang sedang dipelajari secara lebih dekat karena dosen yang pada saat itu sedang mengajar tidak bisa menangani semua mahasiswa secara individu. Oleh karena itu dibutuhkan asisten dosen yang tidak hanya bagus nilai IPK-nya tetapi juga memiliki kemampuan yang baik dalam memberikan penjelasan dan arahan kepada mahasiswa dalam menggunakan aplikasi atau software di laboratorium.

Syarat untuk menjadi laboran atau asisten dosen di STMIK Amikom Surakarta yaitu mengisi 
form pendaftaran lalu menjalani tahapan seleksi berdasarkan minimal nilai ipk 3,0 dan jenjang semester minimal semester 3 , berikutnya menjalani tes tertulis dan tes wawancara. Keseluruhan seleksi dilakukan secara manual oleh Ketua UPT laboratorium. Hal tersebut memakan waktu yang lama dalam prosesnya sehingga ketika perkuliahan aktif sudah dimulai, asisten dosen menjadi terlambat dalam memberikan layanan dan kinerja yang baik di laboratorium praktek kepada mahasiswa. Agar asisten dosen yang direkut sesuai dengan kebutuhan dan memiliki kemampuan yang baik dalam mendampingi mahasiswa saat belajar di laboratorium, maka dalam penelitian ini diusulkan sebuah analisis sistem pendukung keputusan pemilihan asisten dosen di STMIK Amikom Surakarta. Pada penelitian ini menggunakan metode simple Additive Weighting (SAW) untuk mengatasi masalah dalam proses pendaftaran dan pemilihan asisten dosen di STMIK Amikom Surakarta. Metode SAW dipilih karena dalam perhitungannya ditentukan kriteria dan bobot yang digunakan dalam proses pemilihan asisten dosen, untuk selanjutnya dilakukan perankingan berdasarkan nilai akhir dari masing-masing mahasiswa yang telah mengikuti pemilihan asisten dosen. Hasil akhir dari perhitungan menggunakan SAW akan menjadi pertimbangan Ketua UPT laboratorium dalam menentukan mahasiswa yang lolos menjadi asisten dosen, yaitu mahasiswa yang telah menjalani seleksi dan memiliki urutan ranking berdasarkan nilai teratas hingga terbawah dari keseluruhan peserta yang mengikuti seleksi.

Sistem Pendukung Keputusan merupakan sistem yang dibangun untuk mendukung pemecahan masalah atau untuk mengevaluasi suatu peluang dalam pengambilan suatu keputusan[1]. Penelitian yang dilakukan oleh Edo Alfa Rizki adalah membuat sistem pendukung keputusan mahasiswa menjadi asisten dosen menggunakan metode profile matching berbasis web. Penulis merujuk tulisan ini karena kriteria yang digunakan dalam menentukan asisten dosen memiliki beberapa kesamaan dengan penulis yaitu kemampuan, ipk, dan pengalaman menjadi asisten dosen. Meskipun metode yang digunakan penelitian ini berbeda dengan yang penulis gunakan namun berdasarkan kriteria yang ditetapkan, menginspirasi penulis untuk menerapkan metode yang lain yaitu SAW[2]. 51\%

Penelitian yang dilakukan oleh Emi Sita Eriana adalah pemilihan ketua Himtif Universitas Pamulang dengan metode Simple Additive Weighting. Kriteria yang digunakan dalam pemilihan ketua himtif ini adalah IPK, Nilai Tes Wawasan, Nilai Tes Debat Visi Misi, dan Nilai Keaktifan Organisasi. Penulis merujuk penelitian ini karena logika perhitungan yang digunakan sama yaitu SAW dan kriteria penilaian memiliki beberapa kesamaan[3]. Siti Rihastuti dan Afnan Rosyidi dalam tulisannya Analisis Perancangan Sistem Pendukung Keputusan Menggunakan SAW dalam Penerimaan Staf di STMIK Cipta Darma Surakarta, menunjukkan bahwa hasil akhir dari perhitungan metode SAW menunjukkan hasil berupa urutan calon nama staf yang akan diputuskan diterima oleh bagian PSDM [4].

Penelitian yang dilakukan oleh Endang Lestari adalah kolaborasi metode SAW Dan AHP untuk sistem pendukung keputusan penilaian kinerja asisten laboratorium. Penulis merujuk penelitian ini karena bisa mengetahui bahwa penerapan kedua metode tersebut menghasilkan perhitungan akhir yang saling berhubungan dan membantu pengambil keputusan dalam menilai kinerja asisten laboratorium (metode SAW digunakan untuk menghitung kriteria pengajaran dan metode AHP digunakan untuk menghitung kriteria penelitian, kriteria pengabdian masyarakat, dan kriteria tugas tambahan) [5].

Penelitian yang dilakukan oleh Muhamad Azrino Gustalika, Diovianto Putra Rakhmadani, Alon Jala Tirta Segara adalah penerapan metode SAW pada sistem informasi pemilihan asisten praktikum. Penelitian ini dilakukan dengan menetapkan nilai akademik (IPK semester terakhir), microteaching, kepribadian, dan wawancara sebagai kriteria dalam menilai dan menentukan asisten praktikum menggunakan metode SAW. Hasil akhir perhitungan menggunakan metode SAW menunjukkan nilai yang baik dan mampu membantu instansi dalam menentukan asisten praktikum yang sesuai dengan kebutuhan dan memenuhi nilai kriteria [6].

$\begin{array}{lrr} & \text { Ramos Somya dan Retantyo Wardoyo } \\ \text { dalam tulisannya perancangan sistem } & \\ \text { pendukung keputusan seleksi asisten dosen }\end{array}$


menggunakan kombinasi metode Profile Matchingdan TOPSIS Berbasis Web Service. Penerapan metode TOPSIS yang diselaraskan dengan metode profile matching menghasilkan output akhir berupa nama mahasiswa berdasarkan ranking sehingga membantu dosen koordinartor dalam menentukan mahasiswa mana yang akan diterima menjadi asisten dosen [7].

Triana Elizabeth dan Tinaliah dalam tulisannya sistem pendukung keputusan pemilihan asisten dosen menggunakan metode SAW. Dilatarbelakangi kondisi asisten dosen yang kurang aktif, kemampuan yang kurang saat menjelaskan ke adik tingkat dan kurangnya dampak secara positif terhadap perkuliahan yang berlangsung membuat penulis menetapkan 5 (lima) kriteria yang menyeluruh supaya asisten dosen yang direkrut merupakan mahasiswa yang mampu dan berkompeten dalam menjalankan tugasnya. Kriteria tersebut adalah IPK, tes pemrograman, kemampuan mengajar, nilai referensi dan kerja sama. Berdasarkan perhitungan yang telah dilakukan dengan menerapkan metode SAW, diperoleh hasil berupa nama mahasiswa berdasarkan ranking teratas sehingga membantu kepala program studi dalam menentukan siapa saja asisten dosen yang akan diterima dan nilai referensi yang ditetapkan membantu dosen pengampu matakuliah dalam rangka untuk mengetahui siapa saja mahasiswa yang pernah menjadi asisten dosen di semester sebelumnya [8].

Tujuan penelitian ini adalah menganalisis sistem pendukung keputusan menggunakan metode Simple Additive Weighting (SAW) dalam pemilihan asisten dosen di STMIK Amikom Surakarta. Hasil akhir dari penerapan metode SAW adalah nama mahasiswa berdasarkan nilai dan ranking tertinggi, sehingga membantu ketua UPT laboratorium dalam menentukan mahasiswa mana yang akan diterima menjadi asisten dosen. $69 \%$

\section{METODE PENELITIAN}

Langkah-langkah yang dilakukan dalam penelitian ini meliputi:

1. Analisis, yaitu menganalisis permasalahan yang ada, merencanakan apa saja kebutuhan sistem baik secara fungsional maupun non fungsional.

2. Perancangan, pada tahap ini use case diagram digunakan untuk memodelkan sistem yang akan dibuat beserta kriteria yang dipakai dalam proses pemilihan asisten dosen.

3. Pemilihan Alternatif, yaitu menerapkan perhitungan menggunakan metode SAW, yang hasil dari perhitungan tersebut akan dijadikan alat bantu dan pertimbangan dalam menentukan nama-nama mahasiswa yang akan diterima menjadi asisten dosen. Terdapat 4 (empat) kriteria penilaian yang digunakan, yaitu nilai IPK minimal 3,0, minimal semester3, nilai tes tertulis dan nilai tes wawancara. Dari keempat kriteria tersebut, diharapkan output yang didapatkan adalah nama-nama mahasiswa yang memiliki kemampuan dan memenuhi kebutuhan dalam membantu mahasiswa saat belajar praktek di laboratorium.

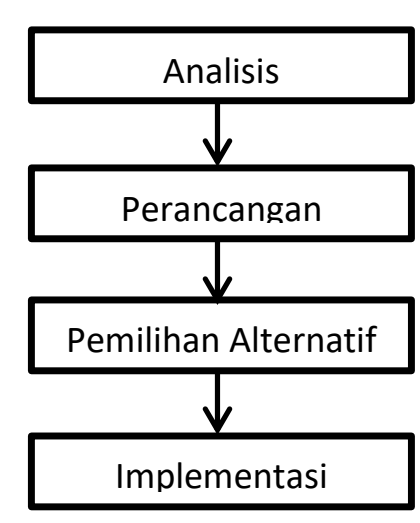

Gambar 1. Alur Penelitian 


\section{HASIL DAN PEMBAHASAN}

3.1. Analisis kebutuhan sistem

a. kebutuhan fungsional sistem :

1) $\log$ in

2) input data pendaftar asisten dosen

3) hasil pemilihan

4) persetujuan ketua UPT laboratorium

b. kebutuhan non fungsional sistem :

1) sistem diakses oleh user
2) sistem dilengkapi dengan pengaman, hanya user yang memiliki hak akses yang bisa masuk ke dalam sistem.

3.2. Perhitungan menggunakan metode Simple Additive Weighting (SAW)

Langkah penyelesaian dalam pemilihan asisten dosen menggunakan metode SAW :

a. Menentukan kriteria yang digunakan dalam penilaian

Tabel 1. Kriteria yang digunakan

\begin{tabular}{|c|c|l|c|}
\hline No. & Kriteria & \multicolumn{1}{|c|}{ Keterangan } & Jenis Kriteria \\
\hline 1 & C1 & Nilai IPK & Benefit \\
\hline 2 & C2 & Minimal Semester & Benefit \\
\hline 3 & C3 & Tes tertulis & Benefit \\
\hline 4 & C4 & Tes wawancara & Benefit \\
\hline
\end{tabular}

b. Memberikan nilai bobot pada masing-masing kriteria

Tabel 2. Bobot kriteria

\begin{tabular}{|c|l|c|c|}
\hline No. & \multicolumn{1}{|c|}{ Kriteria } & Bobot & Bobot preferensi \\
\hline 1 & Nilai IPK & $25 \%$ & 0,25 \\
\hline 2 & Minimal Semester & $20 \%$ & 0,20 \\
\hline 3 & Tes tertulis & $20 \%$ & 0,20 \\
\hline 4 & Tes wawancara & $35 \%$ & 0,35 \\
\hline
\end{tabular}

c. Memberikan skala nilai untuk masing-masing kriteria

Tabel 3. Skala Nilai Kriteria

\begin{tabular}{|c|l|c|c|}
\hline No. & \multicolumn{1}{|c|}{ kriteria } & Skala penilaian & Bobot Nilai \\
\hline \multirow{2}{*}{1} & \multirow{2}{*}{ Nilai IPK } & $>3,01$ & 1 \\
\cline { 3 - 4 } & & $<3,00$ & 0,6 \\
\hline \multirow{2}{*}{2} & \multirow{2}{*}{ Minimal Semester } & $>=3$ & 1 \\
\cline { 3 - 4 } & & $<3$ & 0,5 \\
\hline \multirow{2}{*}{3} & \multirow{2}{*}{ Tes tertulis } & $>85$ & 1 \\
\cline { 3 - 4 } & & $<84$ & 0,4 \\
\hline \multirow{2}{*}{4} & \multirow{2}{*}{ Tes wawancara } & $>90$ & 1 \\
\cline { 3 - 4 } & & $<89$ & 0,4 \\
\hline
\end{tabular}

Berdasarkan hasil seleksi pemilihan asisten dosen, diperoleh data penilaian dan

rating kecocokan dari setiap alternatif (Ai) pada setiap kriteria ( $\mathrm{Ci}$ ) pada 10 nama mahasiswa.

Tabel 4. Data penilaian

\begin{tabular}{|c|l|c|c|c|c|}
\hline No. & \multicolumn{1}{|c|}{ Nama } & Nilai IPK & Minimal Semester & Tes tertulis & Tes wawancara \\
\hline 1 & Imam (A1) & 3,73 & 5 & 89 & 88 \\
\hline 2 & Nadif (A2) & 3,82 & 7 & 80 & 91 \\
\hline 3 & Okta (A3) & 3,67 & 3 & 86 & 92 \\
\hline 4 & Rahmat (A4) & 3,51 & 5 & 82 & 87 \\
\hline 5 & Santosa (A5) & 2,99 & 7 & 89 & 86 \\
\hline 6 & Eko (A6) & 3,14 & 5 & 87 & 92 \\
\hline 7 & Anita (A7) & 3,25 & 3 & 91 & 88 \\
\hline 8 & Riki (A8) & 3,46 & 5 & 85 & 87 \\
\hline 9 & Rindo (A9) & 3,72 & 5 & 83 & 91 \\
\hline 10 & Nanang (A10) & 3,03 & 5 & 86 & 92 \\
\hline
\end{tabular}


d. Membuat matrik keputusan $(X)$ yang dibentuk dari tabel rating kecocokan dari setiap alternatif pada setiap kriteria.

Tabel 5. Nilai Rating kecocokan

\begin{tabular}{|c|l|c|c|c|c|}
\hline No. & Nama & Nilai IPK & Minimal Semester & Tes tertulis & Tes wawancara \\
\hline 1 & Imam & 1 & 1 & 1 & 0,4 \\
\hline 2 & Nadif & 1 & 1 & 0,4 & 1 \\
\hline 3 & Okta & 1 & 1 & 1 & 1 \\
\hline 4 & Rahmat & 1 & 1 & 0,4 & 0,4 \\
\hline 5 & Santosa & 0,6 & 1 & 1 & 0,4 \\
\hline 6 & Eko & 1 & 1 & 1 & 1 \\
\hline 7 & Anita & 1 & 1 & 1 & 0,4 \\
\hline 8 & Riki & 1 & 1 & 1 & 0,4 \\
\hline 9 & Rindo & 1 & 1 & 0,4 & 1 \\
\hline 10 & Nanang & 1 & 1 & 1 & 1 \\
\hline
\end{tabular}

Dari tabel nilai rating kecocokan, dibuat sebuat tabel yang menunjukkan matriks awal dari nilai masing-masing alternatif berdasarkan skala nilai yang ditentukan, seperti Tabel 6 .

Tabel 6. Matriks Awal

\begin{tabular}{|c|c|c|c|c|}
\hline $\mathrm{Ai} / \mathrm{Ci}$ & $\mathrm{C} 1$ & $\mathrm{C} 2$ & $\mathrm{C} 3$ & $\mathrm{C} 4$ \\
\hline $\mathrm{A} 1$ & 1 & 1 & 1 & 0,4 \\
\hline $\mathrm{A} 2$ & 1 & 1 & 0,4 & 1 \\
\hline $\mathrm{A} 3$ & 1 & 1 & 1 & 1 \\
\hline $\mathrm{A} 4$ & 1 & 1 & 0,4 & 0,4 \\
\hline $\mathrm{A} 5$ & 0,6 & 1 & 1 & 0,4 \\
\hline $\mathrm{A} 6$ & 1 & 1 & 1 & 1 \\
\hline $\mathrm{A} 7$ & 1 & 1 & 1 & 0,4 \\
\hline $\mathrm{A} 8$ & 1 & 1 & 1 & 0,4 \\
\hline $\mathrm{A} 9$ & 1 & 1 & 0,4 & 1 \\
\hline $\mathrm{A} 10$ & 1 & 1 & 1 & 1 \\
\hline
\end{tabular}

Sesudah mendapatkan matriks awal selanjutnya melakukan normalisasi keputusan (Xij) dengan menghitung nilai rating kinerja ternormalisasi (Rij) dari alternatif (Ai) pada $R i j\left\{\begin{array}{c}\frac{X i j}{\text { MaxXij } j i k a j a d a l a h k e u n t u n g a n} \text { (benefit) } \\ \frac{\text { MinXij }}{X i j} \text { jikajadalahbiaya (cost) }\end{array}\right.$ setiap kriteria (Ci) berdasarkan persamaan di metode SAW yaitu: jika j adalah biaya (cost)

\section{Keterangan :}

$\mathrm{Ri} \mathrm{j}=$ nilai rating kinerja ternormalisasi

$\mathrm{Xi}=$ nilai atribut yang dimiliki dari setiap kriteria

Max xij = nilai terbesar dari setiap kriteria $i$

Min $\mathrm{xij}=$ nilai terkecil dari setiap kriteria $\mathrm{i}$

Benefit $=$ jika nilai terbesar adalah terbaik

Cost $=$ jika nilai terkecil adalah terbaik

1. Kriteria nilai IPK, termasuk atribut keuntungan (benefit)

$$
\begin{aligned}
& \mathrm{R} 1.1=\frac{1}{\max \{1 ; 1 ; 1 ; 1 ; 0,6 ; 1 ; 1 ; 1 ; 1 ; 1\}}=\frac{1}{1}=1 \\
& \mathrm{R} 2.1=\frac{1}{\max \{1 ; 1 ; 1 ; 1 ; 0,6 ; 1 ; 1 ; 1 ; 1 ; 1\}}=\frac{1}{1}=1
\end{aligned}
$$




$$
\begin{aligned}
& \mathrm{R} 3.1=\frac{1}{\max \{1 ; 1 ; 1 ; 1 ; 0,6 ; 1 ; 1 ; 1 ; 1 ; 1\}}=\frac{1}{1}=1 \\
& \mathrm{R} 4.1=\frac{1}{\max \{1 ; 1 ; 1 ; 1 ; 0,6 ; 1 ; 1 ; 1 ; 1 ; 1\}}=\frac{1}{1}=1 \\
& \mathrm{R} 5.1=\frac{0,6}{\max \{1 ; 1 ; 1 ; 1 ; 0,6 ; 1 ; 1 ; 1 ; 1 ; 1\}}=\frac{0,6}{1}=0,6 \\
& \mathrm{R} 6.1=\frac{1}{\max \{1 ; 1 ; 1 ; 1 ; 0,6 ; 1 ; 1 ; 1 ; 1 ; 1\}}=\frac{1}{1}=1 \\
& \mathrm{R} 7.1=\frac{1}{\max \{1 ; 1 ; 1 ; 1 ; 0,6 ; 1 ; 1 ; 1 ; 1 ; 1\}}=\frac{1}{1}=1 \\
& \mathrm{R} 8.1=\frac{1}{\max \{1 ; 1 ; 1 ; 1 ; 0,6 ; 1 ; 1 ; 1 ; 1 ; 1\}}=\frac{1}{1}=1 \\
& \mathrm{R} 9.1=\frac{1}{\max \{1 ; 1 ; 1 ; 1 ; 0,6 ; 1 ; 1 ; 1 ; 1 ; 1\}}=\frac{1}{1}=1 \\
& \mathrm{R} 10.1=\frac{1}{\max \{1 ; 1 ; 1 ; 1 ; 0,6 ; 1 ; 1 ; 1 ; 1 ; 1\}}=\frac{1}{1}=1
\end{aligned}
$$

2. Kriteria minimal semester, termasuk atribut keuntungan (benefit)

$$
\begin{aligned}
& \mathrm{R} 1.2=\frac{1}{\max \{1 ; 1 ; 1 ; 1 ; 1 ; 1 ; 1 ; 1 ; 1 ; 1\}}=\frac{1}{1}=1 \\
& \mathrm{R} 2.2=\frac{1}{\max \{1 ; 1 ; 1 ; 1 ; 1 ; 1 ; 1 ; 1 ; 1 ; 1\}}=\frac{1}{1}=1 \\
& \text { R3.2 }=\frac{1}{\max \{1 ; 1 ; 1 ; 1 ; 1 ; 1 ; 1 ; 1 ; 1 ; 1\}}=\frac{1}{1}=1 \\
& \mathrm{R} 4.2=\frac{1}{\max \{1 ; 1 ; 1 ; 1 ; 1 ; 1 ; 1 ; 1 ; 1 ; 1\}}=\frac{1}{1}=1 \\
& \mathrm{R} 5.2=\frac{1}{\max \{1 ; 1 ; 1 ; 1 ; 1 ; 1 ; 1 ; 1 ; 1 ; 1\}}=\frac{1}{1}=1 \\
& \text { R6.2 }=\frac{1}{\max \{1 ; 1 ; 1 ; 1 ; 1 ; 1 ; 1 ; 1 ; 1 ; 1\}}=\frac{1}{1}=1 \\
& \mathrm{R} 7.2=\frac{1}{\max \{1 ; 1 ; 1 ; 1 ; 1 ; 1 ; 1 ; 1 ; 1 ; 1\}}=\frac{1}{1}=1 \\
& \mathrm{R} 8.2=\frac{1}{\max \{1 ; 1 ; 1 ; 1 ; 1 ; 1 ; 1 ; 1 ; 1 ; 1\}}=\frac{1}{1}=1 \\
& \mathrm{R} 9.2=\frac{1}{\max \{1 ; 1 ; 1 ; 1 ; 1 ; 1 ; 1 ; 1 ; 1 ; 1\}}=\frac{1}{1}=1 \\
& \mathrm{R} 10.2=\frac{1}{\max \{1 ; 1 ; 1 ; 1 ; 1 ; 1 ; 1 ; 1 ; 1 ; 1\}}=\frac{1}{1}=1
\end{aligned}
$$

3. Kriteria tes tertulis, termasuk atribut keuntungan (benefit)

$$
\begin{aligned}
& \mathrm{R} 1.3=\frac{1}{\max \{1 ; 0,4 ; 1 ; 0,4 ; 1 ; 1 ; 1 ; 1 ; 0,4 ; 1\}}=\frac{1}{1}=1 \\
& \mathrm{R} 2.3=\frac{0,4}{\max \{1 ; 0,4 ; 1 ; 0,4 ; 1 ; 1 ; 1 ; 1 ; 0,4 ; 1\}}=\frac{0,4}{1}=0,4
\end{aligned}
$$




$$
\begin{aligned}
& \mathrm{R} 3.3=\frac{1}{\max \{1 ; 0,4 ; 1 ; 0,4 ; 1 ; 1 ; 1 ; 1 ; 0,4 ; 1\}}=\frac{1}{1}=1 \\
& \mathrm{R} 4.3=\frac{0,4}{\max \{1 ; 0,4 ; 1 ; 0,4 ; 1 ; 1 ; 1 ; 1 ; 0,4 ; 1\}}=\frac{0,4}{1}=0,4 \\
& \mathrm{R} 5.3=\frac{1}{\max \{1 ; 0,4 ; 1 ; 0,4 ; 1 ; 1 ; 1 ; 1 ; 0,4 ; 1\}}=\frac{1}{1}=1 \\
& \mathrm{R} 6.3=\frac{1}{\max \{1 ; 0,4 ; 1 ; 0,4 ; 1 ; 1 ; 1 ; 1 ; 0,4 ; 1\}}=\frac{1}{1}=1 \\
& \mathrm{R} 7.3=\frac{1}{\max \{1 ; 0,4 ; 1 ; 0,4 ; 1 ; 1 ; 1 ; 1 ; 0,4 ; 1\}}=\frac{1}{1}=1 \\
& \mathrm{R} 8.3=\frac{1}{\max \{1 ; 0,4 ; 1 ; 0,4 ; 1 ; 1 ; 1 ; 1 ; 0,4 ; 1\}}=\frac{1}{1}=1 \\
& \mathrm{R} 9.3=\frac{0,4}{\max \{1 ; 0,4 ; 1 ; 0,4 ; 1 ; 1 ; 1 ; 1 ; 0,4 ; 1\}}=\frac{0,4}{1}=0,4 \\
& \mathrm{R} 10.3=\frac{1}{\max \{1 ; 0,4 ; 1 ; 0,4 ; 1 ; 1 ; 1 ; 1 ; 0,4 ; 1\}}=\frac{1}{1}=1
\end{aligned}
$$

4. Kriteria tes tertulis, termasuk atribut keuntungan (benefit)

$$
\begin{aligned}
& \mathrm{R} 1.4=\frac{0,4}{\max \{1 ; 0,4 ; 1 ; 0,4 ; 1 ; 1 ; 1 ; 1 ; 0,4 ; 1\}}=\frac{0,4}{1}=0,4 \\
& \mathrm{R} 2.4=\frac{1}{\max \{1 ; 0,4 ; 1 ; 0,4 ; 1 ; 1 ; 1 ; 1 ; 0,4 ; 1\}}=\frac{1}{1}=1 \\
& \mathrm{R} 3.4=\frac{1}{\max \{1 ; 0,4 ; 1 ; 0,4 ; 1 ; 1 ; 1 ; 1 ; 0,4 ; 1\}}=\frac{1}{1}=1 \\
& \mathrm{R} 4.4=\frac{0,4}{\max \{1 ; 0,4 ; 1 ; 0,4 ; 1 ; 1 ; 1 ; 1 ; 0,4 ; 1\}}=\frac{0,4}{1}=0,4 \\
& \mathrm{R} 5.4=\frac{0,4}{\max \{1 ; 0,4 ; 1 ; 0,4 ; 1 ; 1 ; 1 ; 1 ; 0,4 ; 1\}}=\frac{0,4}{1}=0,4 \\
& \mathrm{R} 6.4=\frac{1}{\max \{1 ; 0,4 ; 1 ; 0,4 ; 1 ; 1 ; 1 ; 1 ; 0,4 ; 1\}}=\frac{0}{1}=1 \\
& \mathrm{R} 7.4=\frac{0,4}{\max \{1 ; 0,4 ; 1 ; 0,4 ; 1 ; 1 ; 1 ; 1 ; 0,4 ; 1\}}=\frac{1}{1}=0,4 \\
& \mathrm{R} 8.4=\frac{0,4}{\max \{1 ; 0,4 ; 1 ; 0,4 ; 1 ; 1 ; 1 ; 1 ; 0,4 ; 1\}}=\frac{0,4}{1}=0,4 \\
& \mathrm{R} \text { 10.4 }=\frac{1}{\max \{1 ; 0,4 ; 1 ; 0,4 ; 1 ; 1 ; 1 ; 1 ; 0,4 ; 1\}}=\frac{1}{1}=1 \\
& \max \{1 ; 0,4 ; 1 ; 0,4 ; 1 ; 1 ; 1 ; 1 ; 0,4 ; 1\}
\end{aligned}
$$

Tabel 7. Matriks Normalisasi

\begin{tabular}{|c|c|c|c|c|}
\hline $\mathrm{Ai} / \mathrm{Ci}$ & $\mathrm{C} 1$ & $\mathrm{C} 2$ & $\mathrm{C} 3$ & $\mathrm{C} 4$ \\
\hline $\mathrm{A} 1$ & 1 & 1 & 1 & 0,4 \\
\hline $\mathrm{A} 2$ & 1 & 1 & 0,4 & 1 \\
\hline $\mathrm{A} 3$ & 1 & 1 & 1 & 1 \\
\hline $\mathrm{A} 4$ & 1 & 1 & 0,4 & 0,4 \\
\hline $\mathrm{A} 5$ & 0,6 & 1 & 1 & 0,4 \\
\hline
\end{tabular}




\begin{tabular}{|c|c|c|c|c|}
\hline A6 & 1 & 1 & 1 & 1 \\
\hline A7 & 1 & 1 & 1 & 0,4 \\
\hline A8 & 1 & 1 & 1 & 0,4 \\
\hline A9 & 1 & 1 & 0,4 & 1 \\
\hline A10 & 1 & 1 & 1 & 1 \\
\hline
\end{tabular}

Hasil yang diperoleh dari setiap kriteria yang ternormalisasi (Ri), kemudian menentukan hasil nilai akhir ( $\mathrm{Vi})$ yang diperoleh dari penjumlahan dan perkalian elemen (Ri) dengan nilai bobot (W).

$$
\begin{aligned}
& \text { V1 }=(1 * 0,25)+(1 * 0,20)+(1 * 0,20)+(0,4 * 0,35) \\
& =0,25+0,20+0,20+0,14 \\
& =0,79 \\
& \text { V2 }=(1 * 0,25)+(1 * 0,20)+(0,4 * 0,20)+(1 * 0,35) \\
& =0,25+0,20+0,08+0,35 \\
& =0,88 \\
& \text { V3 }=(1 * 0,25)+(1 * 0,20)+(1 * 0,20)+(1 * 0,35) \\
& =0,25+0,20+0,20+0,35 \\
& =1 \\
& \text { V4 }=(1 * 0,25)+(1 * 0,20)+(0,4 * 0,20)+(0,4 * 0,35) \\
& =0,25+0,20+0,08+0,14 \\
& =0,67 \\
& \text { V5 }=(0,6 * 0,25)+(1 * 0,20)+(1 * 0,20)+(0,4 * 0,35) \\
& =0,15+0,20+0,20+0,14 \\
& =0,69 \\
& \text { V6 }=(1 * 0,25)+(1 * 0,20)+(1 * 0,20)+(1 * 0,35) \\
& =0,25+0,20+0,20+0,35 \\
& =1 \\
& \text { V7 }=(1 * 0,25)+(1 * 0,20)+(1 * 0,20)+(0,4 * 0,35) \\
& =0,25+0,20+0,20+0,14 \\
& =0,79 \\
& \text { V8 }=(1 * 0,25)+(1 * 0,20)+(1 * 0,20)+(0,4 * 0,35) \\
& =0,25+0,20+0,20+0,14 \\
& =0,79 \\
& \text { v9 } \quad=(1 * 0,25)+(1 * 0,20)+\left(0,4^{*} 0,20\right)+(1 * 0,35) \\
& =0,25+0,20+0,08+0,35 \\
& =0,88 \\
& \mathrm{~V} 10=(1 * 0,25)+(1 * 0,20)+(1 * 0,20)+(1 * 0,35) \\
& =0,25+0,20+0,20+0,35 \\
& =1
\end{aligned}
$$

Tabel 8. Preferensi

\begin{tabular}{|c|l|c|}
\hline $\begin{array}{l}\text { Ranking berdasarkan } \\
\text { nilai preferensi }\end{array}$ & Nama/Alternatif & Nilai Preferensi \\
\hline 1 & Okta (A3) & 1 \\
\hline 2 & Eko (A6) & 1 \\
\hline 3 & Nanang (A10) & 1 \\
\hline 4 & Nadif (A2) & 0,88 \\
\hline 5 & Rindo (A9) & 0,88 \\
\hline 6 & Imam (A1) & 0,79 \\
\hline 7 & Anita (A7) & 0,79 \\
\hline 8 & Riki (A8) & 0,79 \\
\hline 9 & Santosa (A5) & 0,69 \\
\hline 10 & Rahmat (A4) & 0,67 \\
\hline
\end{tabular}


Kriteria yang digunakan dalam pemilihan asisten dosen adalah nilai IPK (25\%), minimal semester (20\%), tes tertulis (20\%), dan tes wawancara (35\%). Dari hasil perhitungan menggunakan SAW terhadap 10 mahasiswa, dihasilkan ranking nama calon asisten dosen berdasarkan nilai akhir. Dapat disimpulkan bahwa nilai akhir tersebut bisa digunakan oleh ketua UPT laboratorium untuk dijadikan rujukan (preferensi) untuk menentukan mahasiswa mana yang akan diterima sebagai asisten dosen.

\section{KESIMPULAN}

Berdasarkan analisis sistem pendukung keputusan dalam pemilihan asisten dosen menggunakan metode SAW di STMIK Amikom Surakarta, dapat disimpulkan bahwa metode SAW dapat dijadikan gambaran informasi tentang kriteria apa saja yang diperlukan dalam proses pemilihan asisten dosen dan metode ini dapat menghasilkan urutan ranking berdasarkan nilai tertinggi untuk dijadikan pertimbangan Ketua UPT laboratorium dalam menentukan mahasiswa yang lolos menjadi asisten dosen.

\section{SARAN}

Terkait penerapan metode SAW dalam pemilihan asisten dosen, penulis menyarankan untuk penelitian kedepannya dapat menggunakan metode lain atau metode gabungan supaya dapat dibandingkan dan diketahui hasilnya, metode mana yang paling membantu dalam pengambilan keputusan oleh Ketua UPT laboratorium.

\section{DAFTAR PUSTAKA}

[1]. Kusrini. Konsep dan Aplikasi Sistem Pendukung Keputusan. Andi Offset.Yogyakarta. 2007.

\section{Publikasi dalam prosiding}

[2] Rizki, Edo Alfa. Sistem Pendukung Keputusan Mahasiswa Menjadi Asisten Dosen Menggunakan Metode Profile Matching Berbasis Web. Seminar Nasional Teknologi Informasi dan Komunikasi-2020 hal.301. eISSN: 2685-5615. p-ISSN: 2715-5315.

\section{Publikasi dalam jurnal}

[3] Eriana, Emi Sita. Pemilihan Ketua Himtif Universitas Pamulang Dengan Metode Simple Additive Weighting. Jurnal IImu Komputer JIK Vol. III No. 01 Januari 2020 hal.5.

[4] Rihastuti, Siti; Rosyidi, Afnan. Analisis Perancangan Sistem Pendukung Keputusan Menggunakan SAW dalam Penerimaan Staf di STMIK Cipta Darma Surakarta. Jurnal Teknologi Informasi Universitas Respati Indonesia, Volume 6 Nomor 2 Desember 2020, p-ISSN : 1693-3672, e-ISSN : 26231700.

[5] Lestari, Endang. Kolaborasi Metode SAW Dan AHP Untuk Sistem Pendukung Keputusan Penilaian Kinerja Asisten Laboratorium. Jurnal Sistem Informasi (JSI), VOL.9, NO.1, April 2017 hal.1204. ISSN Print : 2085-1588 ISSN Online :2355-4614 http://ejournal.unsri.ac.id/index.php/jsi/in dex.

[6] Gustalika,Muhamad Azrino; Rakhmadani, Diovianto Putra; Segara, Alon Jala Tirta. Penerapan Metode SAW pada Sistem Informasi Pemilihan Asisten Praktikum. 2021. Jurnal Media Informatika Budidarma 5 (3), hal. 813-823. https://ejurnal.stmikbudidarma.ac.id/index.php/mib.

[7] Somya,Ramos; Retantyo Wardoyo. Perancangan Sistem Pendukung Keputusan Seleksi Asisten Dosen Menggunakan Kombinasi Metode Profile Matching dan TOPSIS Berbasis Web Service. Jurnal IImu Komputer dan Informatika hal.44, Vol. 5 No. 1 Juni 2019. ISSN: 2621-038X, Online ISSN: 2477-698X.

[8] Elizabeth, Triana;Tinaliah. Sistem Pendukung Keputusan Pemilihan Asisten Dosen Menggunakan Metode SAW. Jurnal Teknik Informatika dan Sistem Informasi ISSN 2407- 4322 Vol. 7, No. 1, April 2020, Hal. 7180 E- ISSN 2503- 293371. 